\title{
To Study the Difference in Drug Users \& Non Users for Stress, Personality, \& Coping Strategies
}

\author{
Harish Kumar Sharma ${ }^{1}$, Jaspreet Singh ${ }^{2}$ \\ Department of Psychology, S.B.S. Government College, Kotkapura, Punjab, India \\ Email address: \\ Sharmaharish361@gmail.com (H. K. Sharma),harish_sbs@yahoo.com (H. K. Sharma)
}

\section{To cite this article:}

Jaspreet Singh, Jaspreet Singh. To Study the Difference in Drug Users \& Non Users for Stress, Personality, \& Coping Strategies. Psychology and Behavioral Sciences. Vol. 4, No. 6, 2015, pp. 194-203. doi: 10.11648/j.pbs.20150406.11

\begin{abstract}
Stress, personality and coping strategies are important determinants of drug using behaviour. To observe the differences between drug users and non users on such factors, the study was conducted. 240 adolescent male students from different schools and colleges of Punjab with age range 16-25 years from middle class socioeconomic background were the sample. Results indicated higher perceived stress in drug users than non users. It was also found that drug users were higher in neuroticism, extraversion, openness and conscientiousness, but on agreeableness no significant difference was found. Significant differences were also found on coping strategies. Drug users score higher on denial, projection and regression but lower on isolation and turning against self than non users.
\end{abstract}

Keywords: Stress, Personality, Coping, Drug Use

\section{Introduction}

According to the World Health Organization (WHO) substance abuse is persistent or sporadic drug use inconsistent with or unrelated to acceptable medical practice (1999). The picture is grim if the world statistics on the drugs scenario is taken into account. With a turnover of around $\$ 500$ billion, it is the third largest business in the world, next to petroleum and arms trade. About 190 million people all over the world consume one drug or the other [63].

Goldstein and Kalant (1990) observed that some countries have a long history of traditional medicine whereas in other countries the same drug may be declared illicit and illegal. Social consensus cultural constraints and permission contribute to the shaping of public attitude and practice with respect to drug. Alcohol in western societies, cannabis in the Muslim societies and hallucinogen in Native American religious illustrate how socially accepted drugs are incorporated into the traditional value, practice of a society. Whatever the way drugs are accepted socially and religiously, if these have damaging effects on health, then its use is not medically recommendable. Drug abuse is defined as taking a drug for reasons other than medical in an amount, strength, frequency or manner that damages the physical or mental functioning [51].

Continue use of some drugs can result into physiological and psychological dependence. It is a state where discontinuing such drugs can result into painful and unpleasant withdrawal symptoms. Thus drug addiction is a serious state where individual find difficult to get rid of having drugs. According to the traditional medical usage addiction refers to a condition brought about by the repeated administration of any drug, whereby the continued use of such a drug is necessary to maintain normal physiological function and discontinuance of the drug results in abnormal physical and mental symptoms [49]. Glenn (1987) has pointed out that substances most frequently associated with dependence are those with pain killing potential. The pain killer i.e., drugs work by suppressing pain by altering the ability to respond to pain or by reducing the tension and or anxiety caused by pain.

Several recent developments in psychology as well as in the substance abuse research field have started a renewed interest in the role of personality in the etiology of substance abuse and alcoholism. Excessive drinking during adulthood is one way, that Individuals with an oral character satisfy their frustrated need for oral pleasure [42]. Other psychoanalytic view focus on the anal-sadistic phase of psychosexual development. Alcohol becomes both a means of self destruction and indirect way of getting revenge on parental figure. In some cases it is the weak superego which is unable to stop substance taking behaviour. The super ego is weak, resulting in absence of guilt 
feeling for their behaviour [59].

Both classical and operant models are now generally accepted for explaining the reinforcing nature of the drugs [4] [72] [95]. On the punishment is titled negative reinforcement numerous investigators have used conditioning theories to study drug-seeking behaviour [72].

Cognitive social learning expectations of the development of alcoholism stress the effect of the individuals cognitive expectation concerning the use of alcohol [30][32]. These expectations may be learned through peer and parental modeling, previous experiences with drinking, and exposure to advertising. Thus, people come to expect alcohol to reduce tension and improve negative moods.

Behavioural and genetic studies have consistently indicated that genetic factors contribute to risk of substance abuse [60][67] and have thereby implicated the existence of inherited individual level risk factors for substance use disorders. Personality characteristics constitute an important instance of an individual level risk factor that is both associated with substance abuse risk [78] and substantially heritable [88]. Cook (1998) found extraverts consume more alcohol than introverts. Theoretical developments in the personality field have led to the advancement of hierarchical models of personality based on either a three [20] [38] [87] or a five factor [25] model. These models have facilitated research on personality not only by providing a theoretically coherent structure for wide range of hypothesized personality traits but also by suggesting systematic approaches to the assessment of the major dimensions of personality. Several prominent substance use researchers have proposed theoretical models that accord personality factors a central role in the development of substance abuse [19] [86].

Several other investigators studied personality traits of extraversion and neuroticism and observed that hallucinogen abuser score significantly higher on neuroticism, psychoticism and lie scales but only non-significantly higher on the extraversion scale [65]. Earlier, Mani (1961); Singh \& Akthar (1971); Eysenck \& Eysenck (1979) and Bhasi (1992) reported high score on neuroticism and extraversion in drug dependent individuals. Such correlates were also obtained by other researchers [47] [85].

Researches reviewed by investigators have implicated personality factors associated with substance abuse [78]. However the magnitude of mean difference between the representative sample of substance abusers and non-abusers appear only to be moderate [61]. Nathan (1988) suggested that if personality influences substance abuse risk it does so as one of a myriad of risk factors in a multifactorial system rather than as the effect of a unique configuration of personality characteristics, the possession of which leads inevitably to an addiction i.e., "an addictive personality."

Several investigators studied drug addiction to examine the difference in rigid, anxious, frustration and loneliness of drug user and non-user. Result indicated that drug abuser had higher anxiety and depression as compared to non-user [91] [54].

Stress is another important factor found associated with drug usage behaviour. People who experience high level of stress are more likely to start smoking again than those who experience less stress [12] [79].

Numerous studies have found association between various indices of psychological stress and smoking uptake, childhood abuse and house-hold dysfunction [39], adverse childhood experience [2], Parent divorce [66], negative life events [53] [82], and perceived stress [34] [82] all these factors have been found to increase the risk for smoking uptake.

Another aspect related to drug taking behaviour is the type of coping reactions an individual has learnt in face of stress. In previous paragraphs, it is stated that that drug taking is itself a coping style adopted by some persons in stress. Type of coping reactions an individual has learnt and the strength of those reactions may create difference in drug users and non users. Pohorecky (1991) studied that people drink as a mean of coping with economic stress, job stress and marital problems, often in the absence of social support and that the severe and chronic the stressor, the greater the alcohol consumption.

Several investigators observed that alcohol actually induce the stress response by stimulating hormone released by the hypothalamus, Pituitary and adrenal glands [89] [36] [93].

Coping styles has been defined as a process of managing demands, both external and internal that are appraised as exceeding the resources of person [55].

Researchers have found positive relationship between coping styles and alcoholism [69] [18]. Fromm \& River (1994) found that avoidant coping styles indicates increased levels of alcohol consumption. While on the other hand, other studies found no significant correlation between coping styles and alcoholism [74].

Abraham, Chandrsekaran \& Chitraleka (1997) conducted a study on 100 alcoholics and their wives. They found that significant correlation between all the coping components and alcohol related problems and no correlation were observed between neuroticism and coping behavior. It is evident from both personality and situational variables play a role in determining the coping behavior of the wives of alcoholics.

Michel et al (1999) found that alcoholic women were significantly more likely to favor maladaptive style of coping while non alcoholic women employed significantly more problem solving and emotion based coping strategies. Neither race not age difference significantly influenced the type of coping utilized by women. The profile of coping strategies utilized by alcoholic group in consistent with poor quality of life and compounding of problems.

The vast majority of research linking personality to substance abuse has focused alcoholism. The present study intends to study big five dimensions of personality, stress and coping in substance user and non-user among school adolescent and young adult and college students.

\section{Objectives}

1. To study the difference in stress among substance user and non-user students.

2. To study the difference in neuroticism between substance user and non-user students. 
3. To study the difference in conscientiousness between substance user and non-user students.

4. To study the difference in extraversion between substance user and non-user students.

5. To study the difference in agreeableness between substance user and non-user students.

6. To study the difference in Openness between substance user and non-user students.

7. To study the difference in denial between substance user and non-user students.

8. To study the difference in isolation between substance user and non-user students.

9. To study the difference in projection between substance user and non-user students.

10. To study the difference in regression between substance user and non-user students.

11. To study the difference in turning against self between substance user and non-user students.

\section{Hypotheses}

1. There is no significant difference in stress between substance user and non-user students.

2. There is no significant difference in neuroticism between substance user and non-user students.

3. There is no significant difference in conscientiousness between substance user and nonuser students.

4. There is no significant difference in extraversion between substance user and non-user students.

5. There is no significant difference in agreeableness between substance user and non-user students.

6. There is no significant difference in Openness between substance user and non-user students.

7. There is no significant difference in denial between substance user and non-user students.

8. There is no significant difference in isolation between substance user and non-user students.

9. There is no significant difference in projection between substance user and non-user students.

10. There is no significant difference in regression between substance user and non-user students.

11. There is no significant difference in turning against self between substance user and non-user students.

\section{Methodology}

\subsection{Sample}

240 substance user and 240 non-user students, 120 each from different schools and colleges of Punjab were selected for this study. These students were selected randomly. Mean age of school and college substance user and non-user students were 20.5 years age range being 16-25 years. All these subjects were male and had a middle class socioeconomic background. All these subjects were selected after criteria in terms of their frequency (minimum 4 times a week and duration minimum 6 months) of substance abuse was fixed for the subject to be considered for this study.

\subsection{Tools \& Techniques}

\subsubsection{Revised NEO Personality Inventory}

NEO-Five Factor Inventory (Costa \& McCrae, 1992): The NEO-Five Factor Inventory is a concise measure of the five major dimensions, or domains of personality. The NEO-five factor Inventory (Costa \& McCrae, 1992) is a short version of revised NEO Personality Inventory. It is a 60 -item questionnaire answered on 5-point scale ranging from strongly disagrees to strongly agree and yields scores on the five major domains of personality. These are neuroticism, extraversion, openness, agreeableness and conscientiousness. In the present study NEO-Five Factor Inventory was used. The NEO FFI (the 60 item domain only version) the internal consistencies reported in the manual were: $\mathrm{N}=.79, \mathrm{E}=.79, \mathrm{O}=.80, \mathrm{~A}=.75$, $\mathrm{C}=.83$ respectively. The test retest reliability reported in the manual of the NEO PI-R over 6 years was: $\mathrm{N}=.83, \mathrm{E}=.82$, $\mathrm{O}=.83, \mathrm{~A}=.63, \mathrm{C}=.79$. Validity and item-total correlations of this inventory was also obtained ranged between 21 to 86 .

The Big Five model is a comprehensive, empirical, datadriven research finding. Identifying the traits and structure of human personality has been one of the most fundamental goals in all of psychology. The five broad factors were discovered and defined by several independent sets of researchers [31].These researchers began by studying known personality traits and then factor-analyzing hundreds of measures of these traits (in self-report and questionnaire data, peer ratings, and objective measures from experimental settings) in order to find the underlying factors of personality.

\subsubsection{Perceived Stress Scale}

Perceived Stress Scale [PSS-10] which was created by Cohen et al. (1983). The PSS 10 was created to measure the "experienced level of stress as a function of objective stressful events, coping processes, personality factors" (Cohen et al., p. 386). The PSS10 measures perceived stress by asking participants questions such as, "In the past month, how often have you been upset because of something that happened unexpectedly?" The participants then rated their response given a five-point likert scale of "never," "almost never," "sometimes," "fairly often," and "very often." Responses from all 10 questions were then combined to create a total score for perceived stress. The PSS was designed for use in community samples with at least a junior high school education.

Evidence for Validity: Higher PSS scores were associated with (for example):

Failure to quit smoking

Failure among diabetics to control blood sugar levels

Greater vulnerability to stressful life-event-elicited depressive symptoms

More colds

Health status relationship to PSS: Cohen et al. (1988) show correlations with PSS and: Stress Measures, SelfReported Health and Health Services Measures, Health 
Behavior Measures, Smoking Status, Help Seeking Behavior.

Temporal Nature: Because levels of appraised stress should be influenced by daily hassles, major events, and changes in coping resources, predictive validity of the PSS is expected to fall off rapidly after four to eight weeks.

\subsubsection{Drug Abuse Screening Test (DAST-20) Harvey A. Skinner}

This 20-item instrument may be given in either a selfreport or in a structured interview format; a "yes" or "no" response is requested from each of 20 questions. It is constructed similarly to the earlier Michigan Alcoholism Screening Test (MAST), and the DAST items tend to parallel those of the MAST.

The purpose of the DAST is 1) to provide a brief, simple, practical, but valid method for identifying individuals who are abusing psychoactive drugs; and 2) to yield a quantitative index score of the degree of problems related to drug use and misuse. DAST scores are highly diagnostic with respect to a DSM diagnosis of psychoactive drug dependence. It obtains no information on the various types of drugs used, or on the frequency or duration of the drug use. There is a question regarding multiple drug use, and some of the types of problems caused by drug use/abuse in different areas of life. A brief examination of the individual item responses indicates the specific life problem areas.

A form of the DAST has been adapted for use by adolescents (the word "work" has been replaced by "school").

A factor analysis of the 20 items has indicated that the DAST is essentially a uni-dimensional scale. Accordingly, it is planned to yield only one total or summary score ranging from 0 to 20 , which is computed by summing all items that are endorsed in the direction of increased drug problems. Only two items are keyed for a "No" response: "Can you get through the week without using drugs?" and "Are you always able to stop using drugs when you want to?" A DAST score of six or above is suggested for case finding purposes, since most of the clients in the normative sample score six or greater. It is also suggested that a score of 16 or greater be considered to indicate a very severe abuse or a dependency condition.

An internal consistency coefficient of .92 was obtained for a sample of 256 drug/alcohol abuse clients. Adequate concurrent or convergent validity was reported to have been demonstrated by the fact that the DAST attained 85 percent overall accuracy in classifying clients according to DSM-III diagnosis, and also to have been demonstrated by significant correlations of the DAST scores with frequency of various types of drugs used during the preceding 12 months. The statistical significance of the DAST scores to distinguish between DSM-III diagnosed abuse "cases" from "non-cases" is reported evidence of discriminate validity. The DAST scores were found to be only "moderately correlated" with scores for social desirability and denial.

\subsubsection{Coping Operations Preference Enquiry (COPE: Schutz, 1978)}

Cope is a projective instrument to identify coping mechanisms. The people employ when they encounter unpleasant stimuli. The test presents a number of stories, each story depicting an unpleasant situation in which the central character finds himself/ herself, Respondents are asked to read each story and indicate the degree of each coping mechanism the central character is likely to adopt in each situation. The preference rating of respondents is projection of their own preference for each of the coping patterns. Ratings are summed across stories to indicate overall adoption of coping mechanism. Different coping mechanisms measured in the test are:

1. Denial (D) - a strategy in which the individual denies of having any type of stress.

2. Isolation (IS) - a strategy in which the individual possesses an ability to solve the problem intellectually.

3. Projection $(\mathrm{P})$ - strategy in which the individual places the responsibility on others instead of solving the problem.

4. Regression (R)- a strategy to seek help from others,

5. Turning Against self (TAS) - a strategy to criticize and blame himself/herself for the stress.

Coping and defense mechanisms measured by cope were selected as representative of all coping mechanisms described in psychological literature [73].

Test have high reliability and validity in assessing coping reactions.

The t-test was used as a statistical technique to find out significance of mean difference on Personality dimensions, stress and coping strategies of substance user and non-user students.

\subsection{Procedure}

First, the permission was taken from the authorities of different Schools and colleges for conducting the study. They were made clear about the purpose and objectives of the study. Before administering the tests, a good rapport was established with the subjects and they were assured of the confidentiality of their responses. The tests were administered on single and in groups of 10 to 15 subjects in two sessions. Before administering the test, required instructions were given in responding to the statements of tests. In the first session, Demographic Data was designed to get the additional information regarding subjects which may be useful in interpretation of data. In the second session the Drug Abuse Screening Test (DAST-20) and Perceived Stress Scale were administered. In the final session Big Five Personality Inventory and Coping Operations Preference Enquiry were administered to the subjects. The demographic data was designed to get the additional information regarding subjects which may be useful in interpretation of data. The subjects were given instructions as per the respective manuals.

\section{Results \& Discusion}

\subsection{Difference in Substance Non Users and Users for Stress}

It was evident from table 1 that there was a significant 
difference in terms of stress score between substance users and non-user students ( $\mathrm{school}$ and college) $(\mathrm{df}=478, \mathrm{t}=21.84, \mathrm{p}$ $<.01)$. A higher mean score $(M=26.09)$ emerged in substance users as compared to non-users $(\mathrm{M}=17.86)$ on stress.

Table 1. The difference in substance non users and users for stress.

\begin{tabular}{lllll}
\hline Variable & Non-User & User & $\begin{array}{l}\text { Standard } \\
\text { Error }\end{array}$ & t - Ratio \\
\hline \multirow{2}{*}{ Stress } & Mean:17.86 & Mean:26.0 & 0.25 & $21.84^{* *}$ \\
\hline
\end{tabular}

$* * \mathrm{p}<.01$ and $* \mathrm{p}<.05$

The hypothesis (1) stated that the substance user students will not differ significantly from non-user students in their stress. The finding of the study was not in accordance with the stated hypothesis (1) and hence the hypothesis was rejected.

There are a large number of stressors which may be associated with substance use. Some of these stressors include natural disasters, poverty, stressful life events, and daily hassles [13]. Furthermore, stress plays a prominent role in the perpetuation of drug addiction [45].

Agnew and White (1992) found that negative life events were modestly related to alcohol, marijuana, and other illicit drug use.

Brown (1989) found that substance-using adolescents reported more stressful life events than non-substance users. King, Beals, Manson, and Trimble, (1992) found that higher stress led to greater illicit drug use, but not alcohol use.

Cerbone and Larison (2000) concluded that stress does primarily lead to substance use; however, the relationship is not unidirectional. That is, individuals can use substances in an attempt to self-medicate for their stress, or stress can result from substance use. Furthermore, stress is associated with drug cravings and addiction relapse [81].

\subsection{Difference in Substance Non Users and Users for Personality}

Table 2. The difference in substance non users and users for personality.

\begin{tabular}{lllll}
\hline Variables & Nonuser & User & $\begin{array}{l}\text { Standard } \\
\text { error }\end{array}$ & t-ratio \\
\hline Neuroticism & $\begin{array}{l}\mathrm{M}=39.33 \\
\mathrm{Sd}=2.42\end{array}$ & $\begin{array}{l}\mathrm{M}=43.64 \\
\mathrm{Sd}=2.78\end{array}$ & .15 & $18.07 *$ \\
Extraversion & $\mathrm{M}=37.6$ & $\mathrm{M}=38.8$ & .16 & $5.38^{* *}$ \\
Openness & $\mathrm{Sd}=2.53$ & $\mathrm{Sd}=2.33$ & .16 & \\
& $\mathrm{M}=38.16$ & $\mathrm{M}=39.25$ & .17 & $4.63^{* *}$ \\
Agreeableness & $\mathrm{Sd}=2.64$ & $\mathrm{Sd}=2.51$ & .17 & 1.8 \\
& $\mathrm{M}=38.02$ & $\mathrm{M}=38.48$ & .18 & $7.48 * *$ \\
Conscientiousness & $\mathrm{Sd}=2.91$ & $\mathrm{Sd}=2.58$ & & \\
\hline
\end{tabular}

$* * \mathrm{p}<.01$ and $* \mathrm{p}<.05$

Table 2 further showed a significant difference in terms of neuroticism between substance user and non-user students $(\mathrm{df}=238, \mathrm{t}=8.07, \mathrm{p}<.01)$. The higher mean score of substance users $(\mathrm{M}=26.09)$ as compared to non-users $(\mathrm{M}=$ 17.86) showed that substance users are high on neuroticism as they were more impulsive, optimistic, restless and aggressive than their non-users counterparts. The hypothesis (2) that there is no significant difference for neuroticism in drug users and non users was rejected.

High neuroticism score increases the chance of drug use. Reason is relation between neuroticism and stress. Anxious people are more stress vulnerable.

Table 2 indicated that there was a significant difference in terms of extraversion between substance user and non-user students $(\mathrm{df}=478, \mathrm{t}=5.38, \mathrm{p}<.01)$. A higher mean score of substance users $(M=38.8)$ than the non-users $(M=37.6)$ on extraversion indicated that substance users were high on extraversion, i.e., they had many friends, crave excitement, care free, aggressive and lose the temper easily as compared to non-users. The hypothesis (4) that there is no significant difference for extraversion between drug users \& non users was rejected.

Extraversion relates to drug use probably they were excitement seeker so just to have chance excitement became drug user. Several investigators observed that drug abusers are more active, sociable, high risk taker, impulsive and expressive, assertive. However they were less responsible and had poor attitude toward morality and were neurotics as well [5] [64]. Much like the earlier findings [22] [40] [78], the results of present study demonstrated that substance abusers had significantly scored higher on Neuroticism and Extraversion as compared to non-substance abusers. Substance abusers were more anxious, hostile, vulnerable to stress and depressive traits. They had more excitement seeking and assertive tendency as compared to normal subjects. This finding also consistent with earlier studies which showed that substance abusers had scored higher on Neuroticism and showed more neurotic tendencies as compared to non-substance abusers [33] [83] [77] [25] [17] [75] [50]. However, our results directly contradict those of some previous researches [35] [70] [71] [77]. Extraversion is primarily an interpersonal dimension [25].

Table 2 showed a significant difference in terms of openness between substance user and non-user students ( $\mathrm{df}=$ $478, \mathrm{t}=4.63, \mathrm{p}<.01)$. The higher mean score of substance users $(\mathrm{M}=39.25)$ as compared to non-users $(\mathrm{M}=38.16)$ showed that substance users are higher on openness as they were more impulsive, optimistic, restless and aggressive than their non-users counterparts. The hypothesis (6) that there is no significant difference on extraversion between drug users $\&$ non users was rejected.

The same results were obtained by Brooner et al.(1993). Based on the assumption that drug addicts initially have chosen a radical action such as consumption of drugs, either as recreational use or as a means to handle an experienced problem. Openness scale reflects the cognitive style of an individual. Earlier studies reported that substance abusers scored higher on this dimension of personality as compared to non substance abusers [41] [77].

However, table 2 showed on agreeableness there was no significant difference observed between substance users and non-user students. It can be concluded from this result that 
agreeableness has no relation with drug using behavior. The hypothesis (5) that there is no significant difference for agreeableness between drug users \& non users was accepted.

Table 2 indicates that there was a significant difference in terms of conscientiousness between substance user and nonuser $(\mathrm{df}=478, \mathrm{t}=7.48, \mathrm{p}<.01)$. A higher mean score of substance users $(M=42.11)$ than the non-users $(M=40.45)$ conscientiousness reflected that substance users were more organized and efficient than non user. It also means that the drug users plan their behavior more than non users. The hypothesis (3) that there is no significant difference for conscientiousness in drug users and non users was rejected.

Conscientiousness measures the level of control, organization and determination. Conscientiousness is a tendency to show self-discipline, act dutifully and aim for achievement. In the present study substance abusers scored higher on this scale as compared to non substance abusers. This implied that substance abusers had a higher opinion of their abilities and admits that they were often prepared and competent as compared to non-substance abusers. They were driven to succeed. However the results were contradictory to the findings of Charu Dubey, Meenakshi Arora, Sanjay Gupta, and Bipin Kumar, 2010; Flory et. al, 2002, Martin \& Sher, 1994; Malouff, Thorsteinsson, Rooke, \& Schutte, 2007; Trull \& Sher, 1994; Tucker et. al, 2005; Walton \& Roberts, 2004.

Nevertheless, the result of present study did not consistent with earlier studies. The lack of a significant difference may reflect that substance abusers are not more open to new actions and ideas which are among the Openness to experience facets. This reflects that they have narrow interest and imagination and muted in display of emotions. Substance abusers reported that they have lack of attentiveness to inner feelings and intellectual curiosity.

Agreeableness scale reflects a tendency to compassionate and cooperation. Substance abusers and nonsubstance abusers did not differ significantly on this scale. Although substance abusers scored, lower on Agreeableness as compared to nonsubstance abusers. Agreeableness is associated with positive interpersonal qualities such as altruism and positive attitudes towards others. These are traits not commonly associated with the hardened life of drug addicts. Hence, a lower Agreeableness score is unsurprising, but this result is contrary to Brooner et al. (1993). Hence, the no significant agreeableness score is unexpected and difficult to explain.

\subsection{Difference in Substance Non Users and Users for Coping Strategies}

Table 3 also reflected the differences between users \& non users for coping strategies. It showed a significant difference in terms of denial as coping strategy between substance user and non-user students $(\mathrm{df}=478, \mathrm{t}=4.45, \mathrm{p}<.01)$. The higher mean score of substance users $(\mathrm{M}=16.93)$ as compared to non-users $(\mathrm{M}=15.87)$ showed that substance users applied denial more than non users in facing stress. Thus the hypothesis (7) that there is no significant difference for denial in substance users \& non user's students was rejected.
Denial was found preferable coping strategy of drug user. This coping strategy, they feel restrained few negative consequences of drug user.

Table 3. The differences in substance non users and users for coping strategies.

\begin{tabular}{lllll}
\hline Variables & Nonuser & User & Standard error & t-ratio \\
\hline \multirow{2}{*}{ Denial } & $\mathrm{M}=15.87$ & $\mathrm{M}=16.93$ & .16 & $4.45^{* *}$ \\
& $\mathrm{Sd}=2.53$ & $\mathrm{Sd}=2.69$ & & \\
Isolation & $\mathrm{M}=20.74$ & $\mathrm{M}=19.49$ & .21 & $4.53^{* *}$ \\
& $\mathrm{Sd}=3.27$ & $\mathrm{Sd}=2.73$ & & \\
Projection & $\mathrm{M}=17.12$ & $\mathrm{M}=17.65$ & .18 & $2.09^{*}$ \\
& $\mathrm{Sd}=2.79$ & $\mathrm{Sd}=2.68$ & & \\
Regression & $\mathrm{M}=17$ & $\mathrm{M}=17.98$ & .18 & $3.8^{* *}$ \\
Turning & $\mathrm{Sd}=2.9$ & $\mathrm{Sd}=2.68$ & & \\
against self & $\mathrm{M}=19.25$ & $\mathrm{M}=17.94$ & .21 & $4.61 * *$ \\
\hline
\end{tabular}

$* * \mathrm{p}<.01$ and $* \mathrm{p}<.05$

Table 3 further showed a significant difference in terms of Isolation as coping strategy between substance user and nonuser students $(\mathrm{df}=478, \mathrm{t}=4.53, \mathrm{p}<.01)$. The higher mean score of non-users $(M=20.74)$ as compared to substance users $(M=19.49)$ showed that non users were high in using Isolation as coping strategy than substance users. It means that non users possess more ability to resolve stressful problems intellectually. Thus the hypothesis (8) that there is no significant difference for isolation between substance users \& non user's students. The hypothesis was rejected.

Table 3 further showed a significant difference in terms of Projection as coping strategy between substance user and non-user students $(\mathrm{df}=478, \mathrm{t}=2.09, \mathrm{p}<.05)$. The high mean score of substance users $(\mathrm{M}=17.65)$ as compared to non-users $(\mathrm{M}=17.12)$ showed that substance users do more Projection as coping strategy than non-users. On this basis of these results the hypothesis (9) of no difference for projection as coping strategy between substance users \& non users students was rejected.

Table 3 further showed a significant difference in terms of regression between substance user and non-user students for coping $(\mathrm{df}=478, \mathrm{t}=3.8, \mathrm{p}<.01)$. The high mean score of substance users $(\mathrm{M}=17.61)$ as compared to non-users $(\mathrm{M}=$ 17) indicated that substance users seek others help in stressful situation more than non users. It thus rejects the hypothesis (10) that there is no significant difference for regression between substance users $\&$ non users students was rejected.

Table 3 further showed a significant difference in terms of Turning against self coping strategy between substance user and non-user students $(\mathrm{df}=478, \mathrm{t}=4.61, \mathrm{p}<.05)$. The higher mean score of non-users $(\mathrm{M}=19.25)$ as compared to substance users $(M=17.92)$ showed that substance users are lower in using Turning against self as coping strategy than their non-users counterparts. It means that substance users blame or criticize themselves lesser than non users. The hypothesis (11) that there is no significant difference in use of turning against self as coping strategy between substance users \& non users students was rejected.

Various studies that focused on relationship between 
substance use \& coping reactions support above findings. It is essential to view this relationship as it is helpful in abstaining \& recovery from drug addiction.

In fact, low overall stress, ability to cope, and social support may predict abstaining from further drug use [48]. Indeed there are many previous studies which suggest coping positively with stress [6] and supportive relationships [8] facilitate SUD recovery.

Wills, Vaccaro and McNamora (1992) examined adolescent and reported that adolescents to cope with stressful life event and environmental risk factor which have been viewed as more proximal predictors of binge drinking and found that children of alcoholics (CoAs) experience higher level of environmental effects and are more likely to associate with peers who use alcohol [15].

Another study found that stress and peer drinking as environmental risk factors that might prospectively predict trajectory group membership. Moreover, children of alcoholics were likely to be exposed to family environment risk. Children of alcoholic were more likely to be of single parent family, family with high level of conflict and those families are with less consistent parental support and discipline. (Chassin, Barrera and Motogomery, 1997).

Hawkin (1992) examined that family structure and family environment (a composite of family conflict, discipline and parent support of Adolescent) raise risk for adolescent substance use and other problem behaviour. Sher (1991) also reported similar findings.

Will, et. al. (1996) has studied drug abusers and found that risky environment is a factor that develops more drug abusers in the single parent family. Stressful life events; conflict and low in discipline are most causative factors.

This later age of onset suggests that binge drinking for this group might represents more developmentally normative "partying" that occurs when adolescents are less subjected to parental supervision. The increases have often with prodrinking social norm of college environments [16].

Bechman, et. al. (1997) examined that increasing drinking after high school was associated with leaving the parental home and acquiring freedom from adult supervision, whereas declining drinking between age 22 and 32 year was associated with entry into marriage and parenthood.

It can be concluded from the all results obtained in this research that drug use definitely relates to stress, personality $\&$ coping strategies. Drug users perceived stress in their life more than non users. The personality of a person predisposes an individual to become more stress vulnerable \& selecting the coping reactions in stress. Extraversion and neuroticism were strong personality traits that can induce stress and put the person to use drugs to face stress. Openness \& conscientiousness were also found to relate with stress \& drug use behavior. All the coping strategies can be applied by the drug users but which strategy would be applied depends upon the personality of the individual. Neurotic individual were using denial, projection, \& regression as their preferred coping strategies. Extravert applied denial as the coping to stress. Openness \& agreeableness were found to linked with projection as coping reaction. Conscientiousness found to be negatively correlated to turning against self. So the personality made the person stress vulnerable and set preferable coping strategies. Such relational network explained the drug use behavior.

\section{References}

[1] Abraham, J., Chandrasekaran, R. and Chitralekha, V.(1997). A Prospective study of treatment outcome in alcohol dependence from a deaddiction centre in india. Indian $\mathrm{J}$ Psychiatry. Jan-Mar; 39(1): 18-23.

[2] Anda, R. F., Croft, J. B., Felitti, V. J., Nordenberg, D., Giles, W. H., Williamson, D. F., Giovino, G. A. (1999). Adverse childhood experiences and smoking during adolescence and adulthood. JAMA., 1999 Nov 3;282(17):1652-8.

[3] Bachman, J. G., Wadsworth, K. N., O'Malley, P. M., Johnston, L. D., Schulenberg, J. E. (1997). Smoking, drinking and drug use in young adulthood: The impacts of new freedoms and new responsibilities. Mahwah, NJ: Erlbaum.

[4] Bandura, A., (1978). Self Efficacy towards a unifying theory of behavioural change. Psychological Review, 84 (191-215).

[5] Barrett, M.E. and Joe, G.W. (1990). Availability of drugs and psychological proneness in opioid addiction. The International Journal of Addiction, 25, (1212).

[6] Beutler, L. E., Moos, R. H., \& Lane, G. (2003). Coping, treatment planning, and treatment outcome: Discussion. Journal of Clinical Psychology, 59(10), 1151-1167.

[7] Bhasi, S. (1992). A Study of Personality, Social identity and self esteem of drug dependent individuals. Unpublished M. Phil Dissertation, Banglore University.

[8] Broome, K. M., Simpson, D. D., \& Joe, G. W. (2002). The role of social support following shortterm inpatient treatment. The American Journal on Addictions, 11(1), 57-65.

[9] Brooner, R.K., Herbst, J.H., Schmidt, C.W., Bigelow, G.E., \& Costa, P.T. (1993). Antisocial personality disorder among drug abusers. Relations to other personality diagnosis and the FiveFactor Model of Personality. The Journal of Nervous and Mental Disease, 181, 313-319.

[10] Brown, S. A. (1989). Life events of adolescents in relation to personal and parental substance abuse. American Journal of Psychiatry, 146, 484-489.

[11] Caplan, R. D., Cobb, S., French, J. R. (1975) Relationships of cessation of smoking with job stress, personality, and social support. Journal of Applied Psychology, Vol 60(2), Apr, 21119. http://dx.doi.org/10.1037/h0076471.

[12] Caplan, R.D., Cobb, S., French, J. R. P., Van Harrison, R., \& Pinneau, S. R. (1975). Job demands and worker health. Ann Arbor, Mich.: Institute for Social Research.

[13] Cerbone, F. G., \& Larison, M. A. (2000). A bibliographic essay: The relationship between stress and substance use. Substance Use \& Misuse 35(5), 757-786.

[14] Charu Dubey, Meenakshi Arora, Sanjay Gupta, and Bipin Kumar. (2010). Five Factor Correlates: A Comparison of Substance Abusers and Non-Substance Abusers. Journal of the Indian Academy of Applied Psychology, January 2010, Vol.36, No.1, 107-114. 
[15] Chassin, L., Barrera, M., and Motogomery, H. (1997). Parent alcoholism as a risk factor. In S. Walchik and L. Sandler (Eds). Handbook of Children's Coping, New York (101-130).

[16] Chassin, L., Presson, C., Pitts, S. and Sherman, S.J. (2000). The natural history of cigarette smoking from adolescence to adulthood in a mid-western community sample. Multiple trajectories and their psychosocial correlates. Health Psychology, 19 (223-231).

[17] Chopra, G.S. (1979). Man and Marijuana. The International Journal of Addictions, 4, 215-247.

[18] Chung, T., Martin, C. S., Grella, C. E., Winters, K. C., Abrantes, A. M., Brown, S. A. (2003) Course of alcohol problems in treated adolescents. Alcsm Clin. Exp. Res.; 27:253-261. [PubMed].

[19] Cloninger, C. (1987). Neurogenetic Adaptive Mechanisms in Alcoholism. 236, (410-416).

[20] Cloninger, C.R. (1987). A systematic method far clinical description and classification of personality variants. Archives of General Psychiatry, 44 (573-588).

[21] Cohen, S., Kamarck, T., and Mermelstein, R. (1983). A global measure of perceived stress. Journal of Health and Social Behavior, 24, 386-396 (The PSS Scale is reprinted with permission of the American Sociological Association).

[22] Cohen, N.L., Ross, E.C., Bagbay, M.R., Parvolden,P., \& Kennedy, S.H. (2004). The five factor model of personality and antidepressant medication compliance. The Canadian Journal of Psychiatry, 49, 106-113.

[23] Cook, M., Young, A., Taylor, D. B., Anthony P. (1998). Personality Correlates of Alcohol Consumption. Personality \& Individual Differences. 24(5), 641-647.

[24] Costa, P., and McCrae, R. (1992). Revised NEO personality inventory (NEO-PI-R) and NEO personality inventory (NEOFFI) Manual. Udessa FL: Psychological Assessment Services.

[25] Costa, P.T., Jr. and McCrae, R.R. (1992). Five factors are basic personality and individual differences, 13 (653-665).

[26] Costa, P.T.; Jr., and McCrae, R.R. (1992). Revised NEO Personality inventary (NEO PI-R) and NEO Five Factor Inventory (NEC FFI). Professional Manual, Odessa, FL: Psychological Assessment Resources.

[27] Costa, P. T.; McCrae, R. R. (1976). "Age differences in personality structure: A cluster analytic approach". Journal of gerontology 31 (5): 564-570.

[28] Costa, P. T., Jr., \& McCrae, R. R. (1985). The NEO personality inventory manual. Odessa, FL: Psychological Assessment Resources.

[29] Costa, P. T., Jr., \& McCrae, R. R. (1992). NEO PI-R professional manual. Odessa, FL: Psychological Assessment Resources, Inc.

[30] Cox, W.M., and Klinger, E. (1988). A motivational model of Alcohol use. Journal of Abnormal Psychology, 97, (168-80).

[31] Digman, J. M. (1990). Personality structure: Emergence of the five-factor model. Annual Review of Psychology, 41, 417440.

[32] Donovan, D., Marlatt, G.(1980).Assessment of expectancies and behaviors associated with alcohol consumption. A cognitive-behavioral approach. Journal of studies on alcohol, 12, 41(11); 1153- 85: DOI: 10.15288/jsa.1980.41.1153. Source: PubMed.

[33] Dorus, W., \& Senay, E.C. 1980). Depression, demographic dimensions and drug abuse. American Journal of Psychiatry, 137, 699-704.

[34] Dugan, S., Lloyd, B., \& Lucas, K. (1999). Stress and coping as determinants of adolescent smoking behavior. Journal of Applied Social Psychology, 29, 870-888.

[35] Ebile, J.C., \& Pela, D.A. (1981). Some aspects of drug use among students in Benin City-Nigeria. Drug \& Alcohol Dependence, 8, 265-275.

[36] Eskay, R.L.; Chautard, T.; Torda, T.; \& Hwang, D. (1993).The effects of alcohol on selected regulatory aspects of the stress axis. In: Zakhari, S., ed. Alcohol and the Endocrine System. National Institute on Alcohol Abuse and Alcoholism Research Monograph No. 23. Bethesda, MD: the Institute.

[37] Eysenck H.J., and Eysenck M.W. (1979). Personality and individual difference: A Natural Science Approach, New York: Plenum.

[38] Eysenck, H.J. (1967). The Biological Basis of Personality. Spring field, IL : Charles C Thomas.

[39] Felitti, V. J., Anda, R. F., Nordenberg, D., Williamson, D. F., Spitz, A. M., Edwards V, Koss, M. P., Marks, J. S. (1998). Relationship of childhood abuse and household dysfunction to many of the leading causes of death in adults. The Adverse Childhood Experiences (ACE) Study. Am J Prev Med, May; 14(4): 245-58.

[40] Fisher, L.A., Elias, J.W., \& Ritz, K. (1998).Predicting relapse to substance abuse as a function of personality dimension. Alcohol Clinical Experimental Research, 22, 1047-1049.

[41] Flory, K., Lynam, D., Milich, R., Leukefeld, C., \& Clayton, R. (2002). The relationship among personality, symptoms of alcohol and marijuana abuse, and symptoms of comorbid psychopathology: Results from a community sample. Experimental and Clinical Psychopharmacology, 10, 425-434.

[42] Freud, S. (1937). Analysis terminable and interminable, Int. J., Psycho-Anal; 18:373- 405.

[43] Fromme, K. and Rivet, K. (1994).Young adults' Coping Style as a Predictor of their Alcohol use in Response to Daily Events. Journal of Youth and Adolescence, 23, 85-97.

[44] Glenn, H. Stephen (1987). Substance Dependence (in) Link, William, E. Supra note 6 at (P-43).

[45] Goeders, E. (2003). The impact of stress on addiction. European Neuro psychopharmacology, 13(6), 435-441.

[46] Goldstein, A and Kalant, H. (1990).Drug policy: Striking the right balance, Science, Sep, 28; 249(4976);1513-21.

[47] Gunthey, R.K., and Jain, M. (1997). Neurotic problems and feelings of lnsecurity among high and low drug addicts. Journal of the Indian Academy of Applied Psychology. JanJul; 23(1-2): 55-57.

[48] Hyman, S. M., \& Sinha, R. (2009). Stress-related factors in cannabis use and misuse: Implications for prevention and treatment. Journal of Substance Abuse Treatment, 36(4), 400413. 
[49] Isbell, H. (1981). What to know about Drug Addiction. Public Health Service publication, 90.

[50] Jackson, C.P., \& Matthews, G. (1988). The prediction of habitual alcohol use from alcohol related expectancies and personality. Alcohol and Alcoholism, 23, 58- 63.

[51] Jaffe, J.H. (1991). Drug addiction and drug Abuse. In Gilman, A.G., Rall, T.W. and Nies, A.S. (eds.) Pharmacological Basis of Therapeutica, Pergamon Press, (8th eds.) (522-573).

[52] King, J., Beals, J., Manson, S. M., \& Trimble, J. E. (1992). A structural equation model of factors related to substanuce use among American Indian adolescents. Drugs \& Society, 6(3-4), 253-268.

[53] Koval, J. J., Peterson, L. L. (1999). Stress-coping and other psychosocial risk factors: A model for smoking in grade 6 students. Addictive Behaviors, 24, 207- 218.10.1016/s03064603(98)00037-9[PubMed].

[54] Lather AS; Vasudeva P; Verma P, G.(1997). A study of drug abuse among students as related to personality variables. Journal of the Indian Academy of Applied Psychology. JanJul; 23(1-2): 43-49.

[55] Lazarus, R. S., \& Folkman, S. (1984). Stress, appraisal, and coping. New York: Springer Publishing.

[56] Malouff, J.M., Thorsteinsson, E.B., Rooke, S.A., \& Schutte, N.S. (2007). Alcohol Involvement and the Five-Factor Model of Personality: A Meta-Analysis, Journal of Drug Education, 37, 277-294.

[57] Mani, K. (1961). A comparative study of murderers and violent criminals wing Eysenck Personality Inventory. Indian Journal of Clinical Psychology, 6 (41-44).

[58] Martin, E.D., \& Sher, K.J. (1994).Family history of alcoholism, alcohol use disorders and the Five Factor Model of Personality. Journal of Studies on Alcohol, 55, 81-90.

[59] McClleland, D., Davis, W., Kalin, R., and Wanner, E. (1972). The Drinking Man. New York: Free Press, pp xiv +402.

[60] McGue, M. (1995) Mediator and Moderators of alcoholism inheritance. In J.R. Turner, I.R. Cardon, and J.K. Hewitt (Ed.), Behaviour Genetic Approaches in behavioural Medicine, New York (17-44).

[61] McGue, M., Slutske, W., Taylor, J., and Lacono, W.C. (1997). Personality and Substance use disorders: I Effect of gender and alcoholism subtype. Alcoholism: Clinical and Experimental Research, 21, (513-520).

[62] Michels, J. P., Johnson, P. N., Mallin, R., Thomhill, J. T., Sharma, S., Gonzales, H., Kellet, R. (1999). Coping Strategies of Alcoholic Women, Substance Abuse, Dec., Vol. 20, issue 4, pp 237-248.

[63] Miller, WR. Sanchez, VC. (1993). Motivating young adults for treatment and lifestyle change. In: Howard G., editor. Issues in alcohol use and misuse in young adults. University of Notre Dame Press; pp.55-82.

[64] Nathan, P. (1988). The addictive personality is the behaviour of the addict, Journal of Consulting and Clinical Psychology, $56,(186-188)$.

[65] Nishith, Pallavi, Mueser, K.T., Gupta, and Prabha (1994). Personality and hallucinogen abuse in a college population from India. Personality and Individual Differences, 17, (561-563).
[66] Patton, G. C., Hibbert, M. E., Carlin, J., Shao, Q., Rosier, M., Caust, J. \& Bowes, G. (1996), 'Menarche and the onset of depression and anxiety in Victoria, Australia', Journal of Epidemiology and Community Health, vol. 50, pp. 661-66.

[67] Pickens, R. W., Svikis, D. S., McGue, M., Lykken, D. T., Heston, L. L., Clayton, P. J.(1999). Heterogeneity in the inheritance of alcoholism. A study of male and female twins. Arch Gen Psychiatry, Jan; 48(1); 19-28.

[68] Pohorecky, L.A. (1991). Stress and alcohol interaction: An update of human research. Alcoholism: Clinical and Experimental Research 15(3): 438-459.

[69] Pollack, D. (1966). Coping and avoidance in inebriated alcoholics and normals. Journal of Abnormal Psychology, 71, $417-419$.

[70] Porrata, J.L., \& Rosa, A. (2000). Personality and psychopathology of drug addicts in Puerto Rico. Psychological Reports, 86, 275-280.

[71] Rankin, H., Stockwell, T., \& Hodgson, R. (1982). Personality and alcohol dependence. Personality and Individual Differences, 3, 145-151.

[72] Schuster, C. (1992). Drug seeking behaviour: Implications for theories of drug dependence. In Edwards, G. and Lader, M. (Eds), The Nature of Drug Dependence, Oxford: Oxford University Press.

[73] Schutz, W. (1978). Manual of the coping preference enquiry. Palo Alto, California: Consulting Psychologists Press.

[74] Segrin, C., Menees, M. M. (1996) The impact of coping styles and family communication on the social skills of children of alcoholics. J Stud Alcohol. Jan; 57(1): 29-33.

[75] Shanmugan, E.T. (1979). Personality factors underlying drug abuse among college students, Psychological Studies, 24, 2434.

[76] Sher, K.J. (1991). Children of Alcoholics: A Critical Approach of Theory and Research. Chicago: University of Chicago Press.

[77] Sher, K. J., Bartholow, B. D., Wood, M. D. (2000). Personality and substance use disorders: a prospective study. J Consult Clin Psychol. Oct; 68(5): 818-29.

[78] Sher, K.J., and Trull, T.J. (1994). Personality and disinhibitory psychopathology: Alcoholism and antisocial personality disorder. Journal of Abnormal Psychology, 103, (92-102).

[79] Shiffman, S., Gnyys, M., Richards, T.J., Paty, J. A., Hickcox, M., Kassel, J. D., (1996). Temptations to Smoke After Quitting: A comparison of Lapsers and Maintainers. Health Psychology, Nov., Vol. 15, No. 6, 455-461.

[80] Singh, U.P., and Akthar, S.N. (1971). Criminal and non criminals: A comparative study of their personality. Indian Journal of clinical Psychology, 46, (257-263).

[81] Sinha, R. (2008). Chronic stress, drug use, and vulnerability to addiction. Annals of the New York Academy of Sciences, $1141,105-130$.

[82] Siqueira L., Diab M., Bodian C., Rolnitzky L. (2000). Adolescents become smokers: The roles of stress and coping methods. Journal of Adolescent Health, 27, 399408.10.1016/s1054-139x(00)00167-1 [PubMed]. 
[83] Skinner HA (1982). The Drug Abuse Screening Test. Addict Behav 7(4):363-371.

[84] Skinner, H. A. and Allen, B. A. (1982).Alcohol dependence syndrome: measurement and validation. J Abnorm Psychol. Jun; 91(3): 199-209.

[85] Tarter, R.E. (1988). Are there inherited traits that predispose to substance abuse? Journal of consulting and clinical psychology, 56, (189-196).

[86] Tarter, R.E., Alterman, A.I. \& Edward, K.L. (1985). Vulnerability to alcoholism in men: a behavior-genetic perspective, Journal of Studies on Alcohol, 46, 329- 356.

[87] Tellegen, A. (1991). Personality traits: Issues of definition, evidence, and assessment. In W. M. Grove \& D. Cicchetti (Eds.), Thinking clearly about psychology. Vol. 2. Personality and psychopathology (pp. 10-35). Minneapolis, MN: University of Minnesota Press.

[88] Tellegen, A., Lykken, D. T., Bouchard, T. J., Jr., Wilcox, K. J., Segal, N. L., \& Rich, S. (1988). Personality similarity in twins reared apart and together. Journal of Personalitya nd Social Psychology, 54, 1031-1039.

[89] Tsigos, C., \& Chrousos, G.P.(1995). The neuroendocrinology of the stress response. In: Hunt, W., \& Zakhari, S., eds. Stress, Gender, and Alcohol-Seeking Behavior. National Institute on Alcohol Abuse and Alcoholism Research Monograph No. 29. Bethesda, MD: the Institute.

[90] Tucker, J. S., Ellickson, P. L., Orlando, M., Martino, S. C., Klein, D. J. (2005). Substance use trajectories from early adolescence to emerging adulthood: A comparison of smoking, binge drinking, and marijuana use. J. Drug Issues. 35: $307-332$.

[91] Tylor, D.N., Delpilar, J. (1992). Self esteem, anxiety and drug use. Psychological Reports, 71, (896-898).

[92] Walton, K.E., \& Roberts, B.W. (2004). On the relationship between substance use and personality traits: Abstainers are not maladjusted. Journal of Research in Personality, 38, 515535 .

[93] Wand, G.S., \& Dobs, A.S. (1991). Alterations in the hypothalamic-pituitary-adrenal axis in actively drinking alcoholics. Journal of Clinical Endocrinology and Metabolism. 72(6): 1290-1295.

[94] WHO Expert Committee On Dependence Producing Drug. (1964). 14th Report, No 312 Geneva (9).WHO. Techn. Res. Ser. No.886: 1999. p. 48.

[95] Wilker, L. (1980). Opioid Dependence, New York: Plenum Press.

[96] Will, T.A., McNamara, G., Vaccaro, D., and Hisky. E. (1996). Escalating substance use. A longitudinal grouping analysis from early to middle adolescence. Journal of Abnormal Psychology, 105, (166-180).

[97] Wills, T.A., Vaccoro, D., and McNamara, G. (1992). The role of life events family support, and competence in adolescent substance use: A test of vulnerability and protective factors. American Journal of Community Psychology, 20, (349-374). 